\title{
Advancing Climate Dynamics Toward Reliable Regional Climate Projections
}

\author{
Shang-Ping $\mathrm{Xie}^{1), 2), 3)}$
}

\author{
1) Physical Oceanography Laboratory and Key Laboratory of Ocean-Atmosphere Interaction and Climate in Universities of \\ Shandong, Ocean University of China, Qingdao 266100, P. R. China \\ 2) Scripps Institution of Oceanography, University of California at San Diego, La Jolla, CA 92093-0230, USA \\ 3) International Pacific Research Center and Department of Meteorology, University of Hawaii, Honolulu, HI 96822, USA
}

(Received March 15, 2013; revised March 25, 2013; accepted March 25, 2013)

(c) Ocean University of China, Science Press and Springer-Verlag Berlin Heidelberg 2013

\begin{abstract}
With a scientific consensus reached regarding the anthropogenic effect on global mean temperature, developing reliable regional climate projections has emerged as a new challenge for climate science. A national project was launched in China in 2012 to study ocean's role in regional climate change. This paper starts with a review of recent advances in the study of regional climate response to global warming, followed by a description of the Chinese project including the rationale, objectives, and plan for field observations. The 15 research articles that follow in the special issue are highlighted, representing some of the initial results from the project.
\end{abstract}

Key words global warming; regional climate change; ocean-atmosphere interaction

\section{Introduction}

Atmospheric concentration of carbon dioxide (CO2) has increased from the pre-industrial level of 280 to 397 ppm as of February 2013, and global-mean surface air temperature (SAT) has risen by $0.9^{\circ} \mathrm{C}$ over the past 140 years since reliable estimates began in 1880. Climate models predict that global SAT is to rise further by an additional $2-3{ }^{\circ} \mathrm{C}$ by the end of this century under a likely greenhouse gas (GHG) emission scenario (A1B). Earth climate experienced larger swings as between ice ages and interglacial epochs, but the rapid pace of the current global warming is unprecedented and may be beyond the range natural ecosystems and human society can adapt to. A $2^{\circ} \mathrm{C}$ warming is often viewed as dangerous and a target the international community should act to avoid (Allen et al., 2009).

$200 z_{\lambda}$ marked the 20th anniversary of the United Nations Earth Summit in Rio de Janeiro, Brazil, attended by many heads of state including the Chinese Premier Li Peng and U.S. President George H. Bush. The summit was instrumental in establishing the Kyoto Protocol in 1997. Over these 20 years, CO2 level increased by 40 ppm and global SAT by $0.27^{\circ} \mathrm{C}$. Climate change science has made major strides, public awareness has risen, and urgency to act has intensified (Aldy and Stavins, 2012).

\footnotetext{
* Corresponding author. Tel: 0086-532 66781528,

E-mail: sxie@ucsd.edu
}

Climate change has been flagged as a major challenge facing humanity, and the solution requires the best science and collective efforts by all countries. Heads of state, including the Chinese Premier Wen Jiabao and U.S. President Barack Obama, met in December 2009 to discuss this global challenge at the 10th Conference of the Parties (COP15) in Copenhagen, Denmark. At COP17 in Durban, South Africa, 2011, an agreement was reached to negotiate a legally bounding treaty on climate change by 2020, and establish the Green Climate Fund that disburses $\$ 100$ billion a year to help developing countries to cope with global warming.

Decades of research led to a strong scientific consensus. The Intergovernmental Panel on Climate Change (IPCC) Fourth Assessment Report (AR4) states: 'warming of the climate system is unequivocal,' and 'most of the observed increase in global average temperatures since the mid20th century is very likely due to the observed increase in anthropogenic greenhouse gas concentrations.' As GHG emissions continue to increase, greater warming is likely in store for the 21st century. The magnitude of the future increase in global temperature is uncertain depending on emission pathway, and because of insufficient understanding and constraints on climate models' representation of physical processes such as cloud and aerosol effects. The need to reduce the uncertainty led to concerted efforts for the past two decades to study aerosols, their effects on radiation, cloud, and precipitation.

Global mean temperature is a convenient measure of the state of global climate change but national and local 
governments are more concerned with the change in their specific regions (Kerr, 2011). Northern China suffers from a chronic water shortage. Large cities such as Beijing and Qingdao rely on mega engineering projects that divert water from elsewhere. Such semi-arid regions under stress will be affected disproportionately by climate change if precipitation is to decrease. Stakes for regional climate projection are high as there are suggestions that climate change-induced damages should be a basis for dispensing the Green Climate Fund (Hulme et al., 2011).

Despite high socio-economic demands, science for regional climate change is not yet developed enough for reliable information. Uncertainty of climate projections is much larger for regional change than for global mean temperature. While vertically one-dimensional models offer a reasonable prediction of global temperature, atmospheric circulation and interaction with ocean become crucial for regional climate change. Natural variability is higher on the regional scale than for the global mean, making it more difficult detecting forced change (Deser et al., 2012; Fig.1). With a broad consensus reached within the scientific community regarding the cause and future projection of global temperature, regional dynamics is emerging as a new frontier of climate change science.

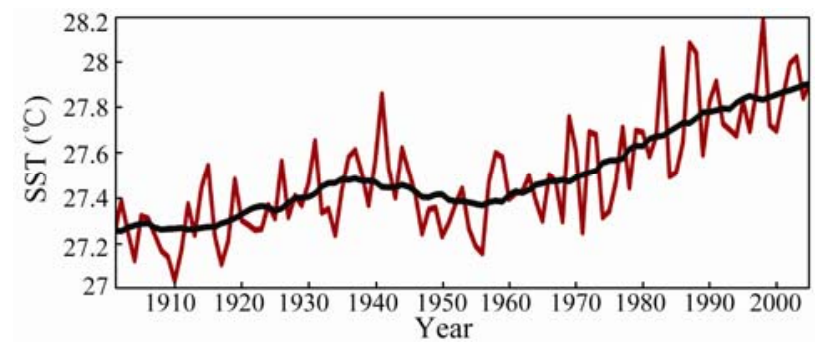

Fig.1 Time series of tropical Indian Ocean SST contains both natural variability and a slow rising trend as represented by the low-passed data in black.

To advance research on this new frontier, a five-year research project entitled 'Response of the Indo-Pacific Oceans to global warming and the effect effect on climate change' (the Ocean Warming project hereafter) was launched in 2012, funded by the Chinese Ministry of Science and Technology under the National Basic Research (973) Program. The goal of the project is to elucidate the dynamics of ocean, atmosphere, and their interaction pertaining to regional climate response to global warming, leading eventually to improved skill and reduced uncertainty in regional climate projection. The project builds on the rapid progress achieved in the Climate Variability and Predictability (CLIVAR) Program in studying regional climate variability that occurs due to internal feedback within the climate system. By directing the attention to global warming, the project aims to discover new dynamical processes and mechanisms unique to forced climate change.

This special issue presents some of initial results from the project. Section 2 provides scientific background. Sections 3 and 4 describe the project and its field cam- paign, respectively. Section 5 highlights papers included in the special issue.

\section{Recent Progress in Regional Climate Change}

Climate is far from being in equilibrium with anthropogenic radiative perturbations. Because of its large thermal inertia, ocean retards the global warming by absorbing most of the GHG-induced increase in downward radiative flux at the top of the atmosphere (Levitus, 2000). In fact, improved estimates of ocean heat content change serve as a crucial constraint on the uncertainties of radiative forcing (Domingues et al., 2008; Lyman et al., 2010). Ocean warming paces the global temperature change. Atmospheric model experiments show that much of the warming over land is mediated by sea surface temperature (SST) increase, not by direct GHG/aerosol forcing. Ocean's role in climate change goes beyond its thermal inertia. This section reviews recent progress in this area.

\subsection{Modes of Variability}

Climate in any given region displays year-to-year variability with spatially coherent patterns. El NiñoSouthern Oscillation (ENSO) is the dominant mode arising from positive feedback between ocean and atmosphere. Research for the past two decades expanded the scope and application of coupled ocean-atmosphere dynamics far beyond ENSO studies in the 1980s. It is now widely recognized that tropical modes of interannual variability originate and derive characteristic spatial structure from ocean-atmosphere interaction. Bjerknes feedback was found important for ENSO, the Atlantic Niño, and Indian Ocean dipole while wind-evaprationSST (WES) feedback is at work in the meridional mode across the equator (Chang et al., 2006). Influential on the summer climate of the Indo-Northwest Pacific and East Asia are the Indian Ocean basin mode and its capacitor effect, the pair being coupled and forming positive feed back coupled-to form positive feedback (Kosaka et al., 2013).

The advance in understanding ocean-atmosphere interaction dynamics has culminated in operational seasonal forecast around the world, with skills in predicting ENSO and its global teleconnections two seasons or more in advance (Wang et al., 2009).

While causing most damage upon landfall, tropical cyclones (TCs) form and grow over ocean, drawing energy from latent heat flux. The TC track prediction has improved and now attains high accuracy. The intensity forecast, however, shows little improvement over time. Evidence is emerging that upper ocean thermal structure affects TC intensification, especially for intense and slow-moving storms (Lin et al., 2008). TC genesis and tracks show considerable year-to-year variability, often in association with coupled ocean-atmosphere modes such as ENSO (Du et al., 2011). 


\subsection{Robust Changes}

A warmer atmosphere contains more water vapor. Midlatitude eddies transport more water vapor poleward. The increase in precipitation in high-latitude regions is a robust change across all models and has received some observational support (Min et al., 2008).

Early studies used atmospheric models coupled to slab ocean mixed layer models. In such an equilibrium response to GHG increase, surface warming is enhanced at both poles because of snow-ice albedo feedback (Manabe and Stouffer, 2007). Noting that the polar amplification is most pronounced in winter when the surface albedo effect is weak, recent studies suggested that the enhanced poleward moist energy transport by eddies is important (Cai, 2005). When a dynamical ocean is considered, however, the polar amplification is limited to the Arctic where summer sea ice is rapidly receding. In the Antarctic, the deep winter mixed layer and the bottom water formation blunt the SST warming. The enhanced (reduced) warming in the Arctic (Antarctic) is robust in transient response to GHG increase across models with a dynamical ocean. These results, first reported in the 1990s, hold up well in more advanced climate models (Manabe and Stouffer, 2007).

In global warming, atmospheric moisture content increases at $7 \%$ per $\mathrm{K}$ increase in global SAT, determined by the Clausius-Clapeyron equation with relative humidity staying constant. The global mean precipitation, constrained by atmospheric radiative cooling, cannot increase that fast, at a slower rate of $2 \%$ per $\mathrm{K}$ instead. Based on the moisture budget, Held and Soden (2006) argued that tropical overturning circulation will slow down to make up the difference between the rates of increase in water vapor and global precipitation. The Walker circulation slowdown is indeed robust across models (Vecchi and Soden, 2007a) and observed in the sea level pressure (SLP) record since 1860 (Vecchi et al., 2006). The change in the Hadley circulation, especially the southern cell, is not robust across models as discussed in the next section.

The width of the Hadley circulation and the subtropical dry zones expand poleward in both hemispheres, a robust feature in global warming simulations (Lu et al., 2007) with observational support (Johanson and Fu, 2009). An explanation points to the increase in dry static stability that reduces baroclinicity and pushes the storm track poleward.

\subsection{Regional Change in Rainfall}

SAT increase is uneven in space, faster over land than ocean in addition to the asymmetry between the Arctic and Antarctic. Nevertheless SAT increases everywhere by the end of this century, with spatial variance representing only a fraction of the global mean (Table 1). Precipitation change, by contrast, is spatially variable to first order, increasing in some regions and decreasing in some others despite the temperature warming everywhere. Its spatial variance is an order of magnitude larger than the global mean, illustrating the inherent difficulty in reliable pro- jection for regional precipitation.

Table 1 CMIP5 Ensemble-means of spatial mean $\left(M_{x, y}\right)$ and variability $\left(\sigma_{x, y}\right)$ of changes in air temperature at $2 \mathrm{~m}$ and precipitation in 22 CMIP3 models

\begin{tabular}{ccc}
\hline Variable $\overline{\bar{\equiv}}$ & $\begin{array}{c}\text { Air temperature at } 2 \mathrm{~m} \\
(\mathrm{~K})\end{array}$ & $\begin{array}{c}\text { Precipitation } \\
\left(\mathrm{mm} \mathrm{mon}^{-1}\right)\end{array}$ \\
\hline$M_{x, y}$ & 1.16 & 1.43 \\
$\sigma_{x, y}$ & 0.45 & 6.95 \\
\hline
\end{tabular}

Note: Changes are defined as the annual mean of 2091-2100 minus that of 2001-2010, normalized by the tropical mean SST warming. The calculations are limited to nearly ice-free regions $\left(60^{\circ} \mathrm{S}-60^{\circ} \mathrm{N}\right)$. From Ma and Xie (2013).

In a warmer climate, the maximum increase in specific humidity occurs at the surface over equatorial oceans because of the Clausius-Clapeyron dependency on background SST. This intensifies three-dimensional gradient and hence advection of moisture by tropical overturning circulation. Specifically, the vertical moisture transport and precipitation minus evaporation (P-E) increase in regions of climatological rising motion, and vice versa. In light of the flat nature of evaporation, this argument predicts a wet-get-wetter pattern of precipitation change (Held and Soden, 2006). This pattern of rainfall change is indeed realized in atmospheric model simulations with spatially uniform increase in SST (SUSI; Xie et al., 2010; Ma and Xie, 2013). Durack et al. (2012) suggested that the observed sea surface salinity change over the past 50 years is consistent with the wet-get-wetter change in E-P.

In coupled models and reality, the SST warming is likely not uniform. The spatial variations affect tropical rainfall by inducing anomalous circulation and modulating convective instability. In coupled models, tropical rainfall is strongly affected by SST warming pattern and follows a warmer-get-wetter pattern, increasing where the SST warming exceeds the tropical mean and vice versa (Fig.2). In the tropics, tropospheric warming is nearly spatially uniform, flattened by fast equatorial waves and following a moist adiabatic vertical profile determined by the tropical mean SST. Local change in convective instability, measured by the vertical difference in moist static energy between the surface and upper troposphere, follows the SST warming pattern and is proportional to relative SST, defined as the deviation from the tropical mean warming. This warmer-get-wetter view predicts that the SST threshold for convection, currently around $27^{\circ} \mathrm{C}$, is dynamic and follows the tropical mean warming. In support of this view, the SST threshold has increased by $0.3^{\circ} \mathrm{C}$ over the past 30 years (Johnson and Xie, 2010).

Percentage change in tropical rainfall $(\mathrm{dP} / \mathrm{P})$ is correlated with relative SST, illustrating the SST pattern effect. Furthermore, differences in SST warming pattern are an important source of uncertainty in projecting precipitation and Hadley circulation changes, explaining one third and $80 \%$ of inter-model variability, respectively (Ma and Xie, 2013). Relative SST is important for extreme events, affecting the distribution of occurrence for tropical cyclones (Vecchi and Soden, 2007b; Knutson et al., 2008) and extratropical storms (Woollings et al., 2012). 

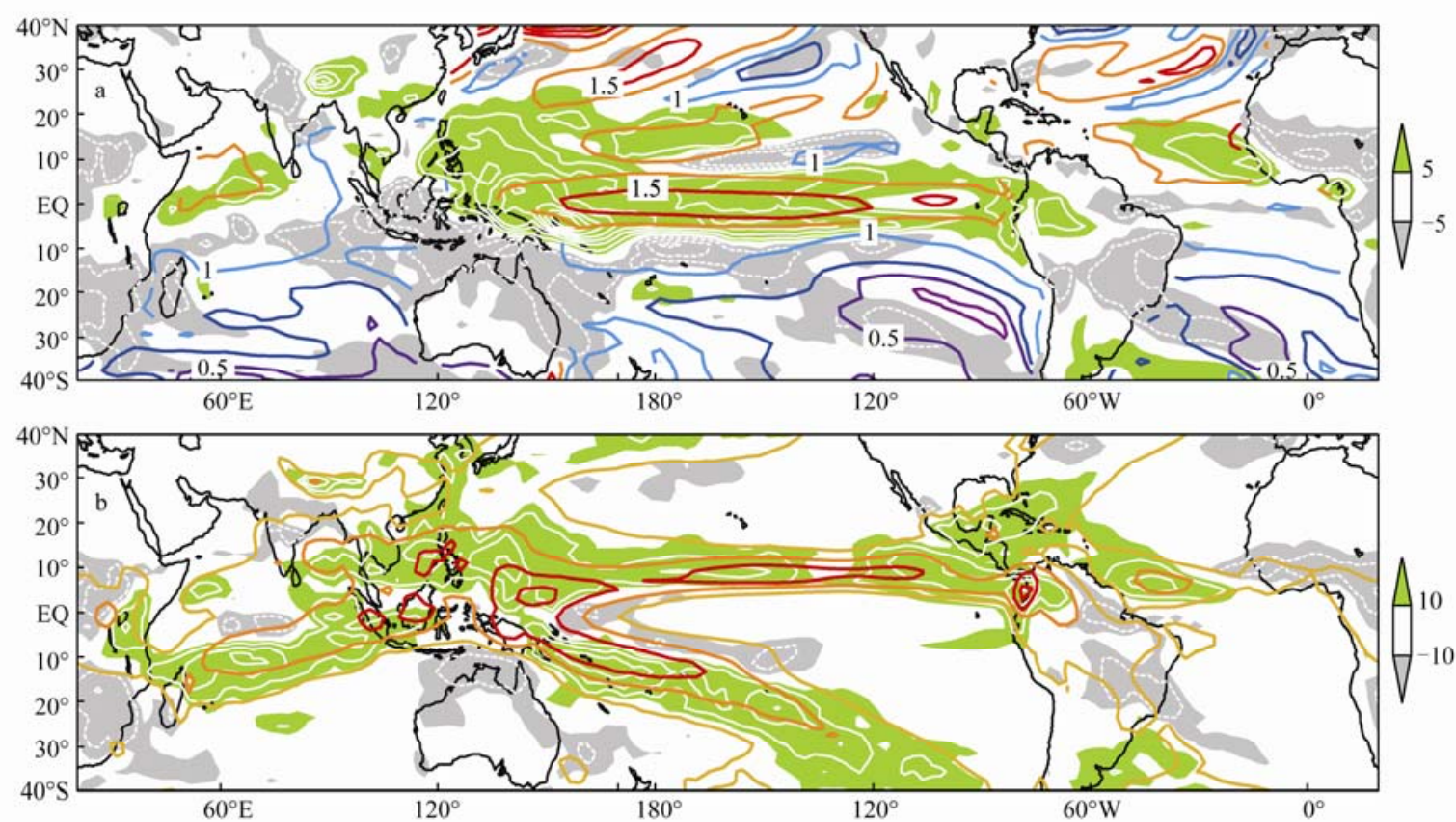

Fig.2 Precipitation response (color shading in $\mathrm{mm} \mathrm{mon}^{-1}$ ) to global warming, along with (a) SST warming (color contours in ${ }^{\circ} \mathrm{C}$ ) in the GFDL coupled model 2.1, and (b) climatological precipitation (color contours at 100, 200, and $300 \mathrm{~mm} \mathrm{mon}^{-1}$ ) in the 2K SUSI run with the GFDL atmospheric model 2.1. White contours represent precipitation change at intervals of 10 and $20 \mathrm{~mm} \mathrm{mon}^{-1}$ in (a) and (b), respectively. Precipitation change follows a wet-get-wetter pattern in SUSI but switches to a warmer-get-wetter pattern in the coupled model where SST warming is spatially variable. From Xie et al. (2010).

\subsection{SST Pattern}

Robust SST patterns in model projections include: reduced warming over the deep water formation regions of the North Atlantic and the Southern Ocean (Manabe and Stouffer, 2007); the equatorial enhanced response over the Pacific (Liu et al., 2005); interhemispheric asymmetry with enhanced/reduced warming in the subtropical Northern/Southern Hemisphere; a zonal dipole of enhanced/ reduced warming in the western/eastern equatorial Indian Ocean. All the SST patterns in the tropical anchor rainfall change following the warmer-get-wetter view (Xie et al., 2010; Chadwick et al., 2013). For example, the equator-enhanced warming increases the frequency of zonal SPCZ occurrence (Cai et al., 2012). Research into pattern formation dynamics is still at the early stage but oceanatmosphere interaction is generally important. Specifically, the dipole warming pattern over the equatorial Indian Ocean involves Bjerknes feedback (Zheng et al., 2010), and the interhemispheric pattern engages WES feedback (Lu and Zhao, 2012).

Attempts to characterize observed regional climate change over ocean have met with difficulty but yielded some initial successes. The challenge arises from sparse and short data records, biases due to measurement change, and small forced signals in the face of large natural variability. Take SST as an example. The increase of $0.5^{\circ} \mathrm{C}$ in the tropical mean over the past 60 years is well beyond the measurement errors but the spatial variations on the order of $0.1-0.2^{\circ} \mathrm{C}$ are not. In fact, widely used SST products gave conflicting results regarding zonal gradient change across the equatorial Pacific (Vecchi and Soden, 2007a). Comparison with independent but complementary observations of nighttime SAT helps differentiate SST datasets (Deser et al., 2010).

More generally, in light of weak signals and inevitable data biases, synthesis of independent data (SST, wind, SLP, cloud and even ocean thermocline depth) based on their mutual physical consistency has proved successful in detecting patterns of change from observations. Equatorial Atlantic change over the past 60 years represents a weakening of climatological features including the cold tongue, easterly trades, and thermocline tilt, accompanied by a reduction in interannual variability (Tokinaga and Xie, 2011). These changes are broadly consistent with model simulations of the 20th century climate. Over the equatorial Indian Ocean, the dipole pattern of change is not clear in SST over the past 60 years but detectable in zonal wind, marine cloudiness, and thermocline depth, in broad agreement with models for a slowdown of the Walker circulation (Tokinaga et al., 2012a).

The slowdown of the Pacific Walker cell for the past 60 years is corroborated from patterns of SLP, wind, marine cloud and thermocline depth changes (Tokinaga et al., 2012a). The atmospheric change is highly sensitive to zonal SST gradient across the Indo-Pacific, and the observed change is reproducible with atmospheric models only if correct SST patterns are prescribed. In particular, bucket SST and nighttime SAT data indicate that the Indo-western Pacific warming is probably less than depicted in HadISST1, ERSST and Kaplan products, as corroborated by the new HadSST3 product (Tokinaga et al., 2012b). 
The Pacific Walker cell has intensified since 1990s (Merrifield, 2011), opposite to the longer-term trend. This illustrates the difficulty detecting modest forced response amid strong natural variability, a problem especially severe over the tropical Pacific. Long-term changes pose a challenge for reanalysis products, which yield results in conflict with marine observations (Han et al., 2010; Tokinaga et al., 2012a, b). At issue is how to constrain long-term change when the amount, type and quality of assimilated data change over time.

\section{A Project for Regional Climate Dynamics}

Thus the SST warming pattern has emerged as an important mechanism regulating changes in precipitation and atmospheric circulation, both in multi-model ensemble mean (robust features) and inter-model variability (uncertainty). Initial diagnostic and modeling results implicate ocean-atmosphere interaction as important. With changes in the mean state, modes of climate variability are likely to change amplitude and spatial pattern, affecting extreme events around the globe via atmospheric teleconnection.

A research project commenced in 2012 and will continue for five years through 2016 to study ocean, atmospheric, and coupled dynamics relevant to regional climate change. Major science questions include

1) How does ocean respond to global warming, and what determines the response?

2) How does ocean-atmosphere interaction shape regional patterns of SST warming and changes in major modes of climate variability?

3) How do spatial variations in SST warming affect monsoon climate over East Asia?

We analyze the Coupled Model Intercomparison Project (CMIP) simulations to identify robust response to global warming across models and assess uncertainties. Our diagnostic studies will include a wide range of observational data from both instrumental and paleoclimate records. Ocean, atmospheric, and coupled model experiments will be performed to test hypotheses derived from diagnostic studies and shed light on dynamics of regional climate change. Mode water ventilation has been identified as a major bias of CMIP-class models. Ship observations are planned over the Northwest Pacific to target relevant physical processes to the mode water ventilation and dissipation, as well as atmospheric boundary layer response to SST gradients.

The project assembles a team of 20 principal investigators from six institutions from around China: Ocean University of China and Nanjing University of Information Science and Technology; Institute of Atmospheric Physics and South China Sea Institute of Oceanology, Chinese Academy of Sciences; First and Second Institutes of Oceanography, State Ocean Administration. The project seeks synergy between major international programs, by applying and extending climate dynamics of CLIVAR to global warming studies of IPCC. Besides the scientific objectives, the project has another important mission of educating the next generation of scientists who will become active and substantive players in the international community of climate change research. Through policyrelevant research, they inform and advise policy makers.

The project is organized into the following four themes.

1) Tropical Indo-Pacific ocean response. Wind stress change is important for tropical ocean circulation, and spatial pattern of SSH change follows shallow-water dynamics (Timmermann et al., 2010). Given that the tropical thermocline forms due to ventilation from the subtropics, surface heat flux change, within and outside the tropics, may affect the stratification and circulation of tropical oceans. In ENSO, thermocline feedback dominates variations in zonal SST gradient. Additional mechanisms are important in global warming, e.g., the dynamic thermostad effect (Cane et al., Z097) and zonal variations in evaporative damping rate (Xie et al., 2010). Theme 1 investigates the tropical ocean response to global warming and how the associated change in heat transport and interaction with the atmosphere shape the spatial pattern of SST warming.

2) Northwest Pacific subtropical gyre response. We choose the Northwest Pacific as a representative midlatitude ocean. Distinct from tropics, midlatitude ocean dynamics features narrow jets, energetic eddies, subduction and ventilation. The Northwest and tropical Pacific Oceans are connected by the ventilated thermocline and atmospheric teleconnection. Characterized by low potential vorticity (PV), mode waters form in the deep winter mixed layer in the Kuroshio extension. Advected by the subtropical gyre, the mode waters of different density stack in the vertical and anchor the eastward subtropical countercurrent (STCC; Kobashi and Kubokawa, 2012). In response to global warming, the mode water weakens in its low-PV characteristic (Luo et al., 2009), and the resultant surface current change leaves a distinctive bandedstructure in SST warming (Xie et al., 2010). Theme 2 investigates the Northwest Pacific response to global warming and relevant interaction between the ocean and atmosphere. In climate models, the low-PV signature of mode water and STCC are both too strong (Xu et al., 2012; Fig.3), and the sources of these biases are unclear. Field observations are planned to examine the ventilation and dissipation of the subtropical mode water (Section 4).

3) Ocean-atmosphere interaction and climate modes. Ocean and atmospheric pattern formation involves their interaction. The interhemispheric asymmetry of enhanced/ reduced warming north/south of the equator decelerates/ accelerates the northern/southern Hadley cell. Superimposed on the deceleration due to the muted hydrological cycle response (Held and Soden, 2006), the deceleration of the northern Hadley cell is robust but the southern cell change is highly variable among models (Ma and Xie, 2013). The deceleration/acceleration of the easterly trade winds reinforces the interhemispheric pattern of SST change via WES feedback. The slowdown of the Indian Ocean Walker cell lifts the thermocline off Indonesia. Interannual IOD variance remains nearly unchanged in 
SST but decreases for thermocline depth and zonal wind (Zheng et al., 2010; Fig.4). In the equatorial Atlantic, a flattened thermocline tilt results in reduced Niño variability (Tokinaga and Xie, 2011). Thus the mean state change affects coupled instability and climate modes. Models disagree on how ENSO responds to global warming (Collin et al., 2010) due partly to strong natural modulations (Stevenson, 2012). Theme 3 investigates ocean-atmosphere interaction processes for changes in the mean state and modes of climate variability.

4) Influences on East Asia. Decreased/increased rainfall in northern/southern China is a major pattern of change over East Asia since 1950. Recent studies show that tropical SST patterns are instrumental in such regional climate change over mid-latitude continents such as China (Li et al., 2010) and North America (Shin and Sardeshmukh, 2011), presumably by exciting atmospheric teleconnection. SST anomalies are also important for interannual variability over East Asia (Xie et al., 2009). Global warming may modulate teleconnections by SST variability (Stevenson, 2012) and hence seasonal predictability. Theme 4 investigates atmospheric dynamics that enables oceanic changes to affect East Asian climate and its predictability. Summer is the rainy season for much of East Asia, and summer precipitation variability/change is a focus. Specifically, our studies will shed light on important questions of what determines large-scale atmos-
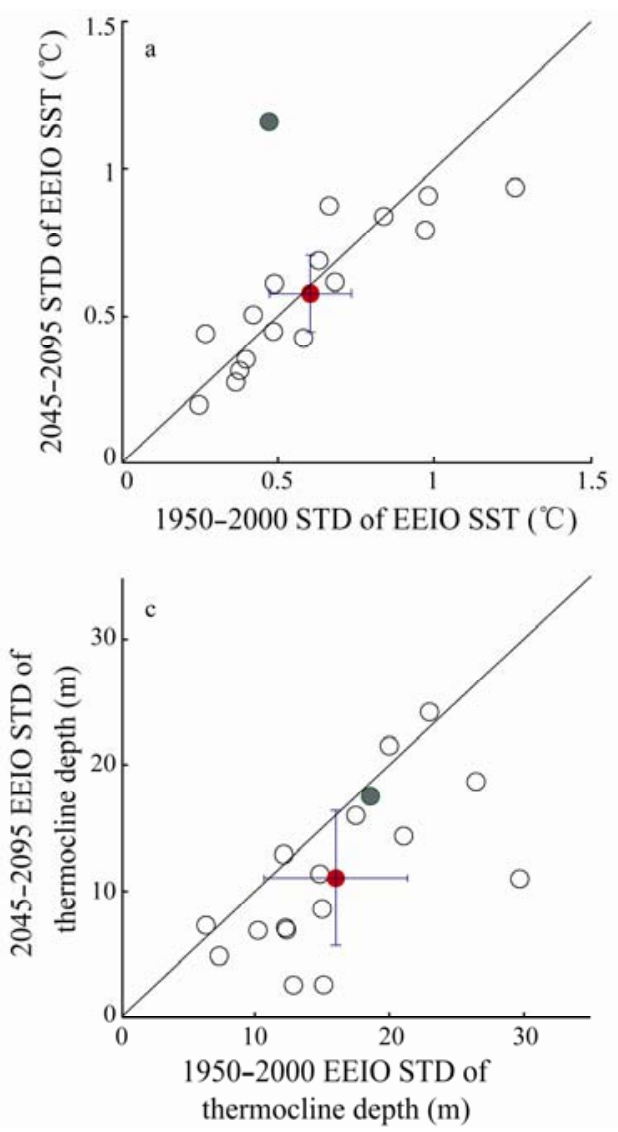

pheric circulation change, and how the large-scale change affects East Asian rainfall via regional/local dynamics and land-atmosphere interactions.
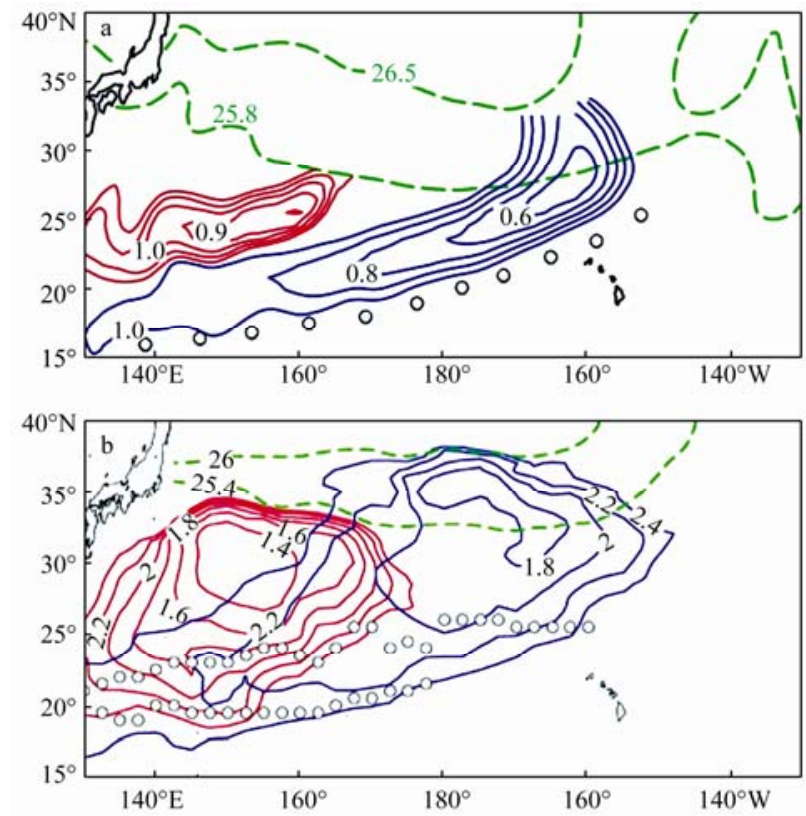

Fig.3 Potential vorticity $\left(10^{-10} \mathrm{~m}^{-1} \mathrm{~s}^{-1}\right)$ on core mode water isopycnals in (upper panel) a climate model and (lower) observations.
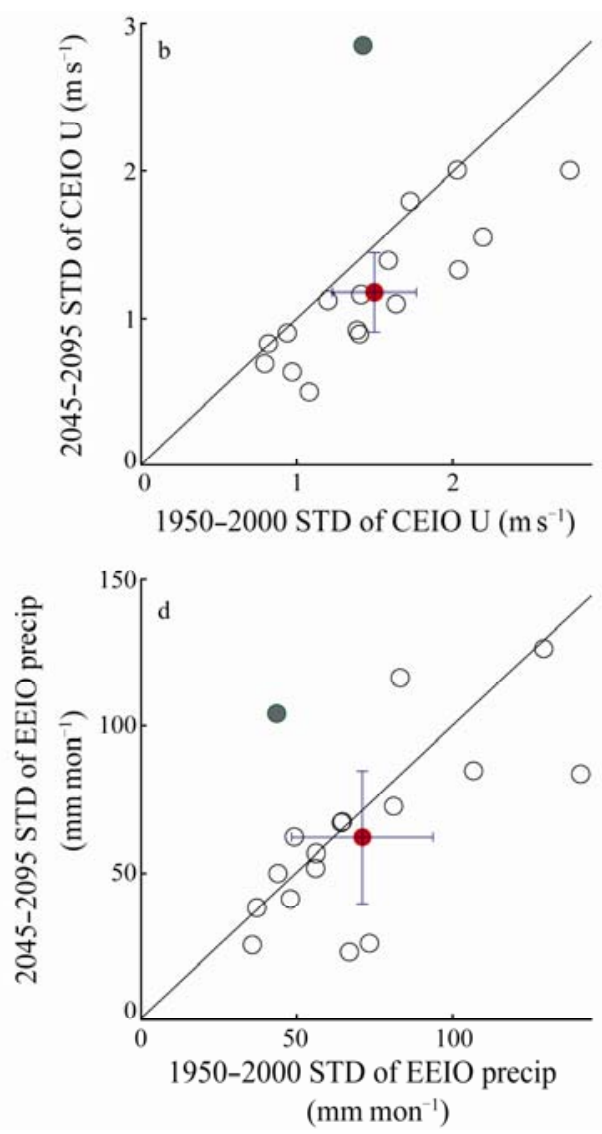

Fig.4 The scatter plots of standard deviations of (a) eastern EIO SST $\left({ }^{\circ} \mathrm{C}\right)$, (b) central EIO zonal wind $\left(\mathrm{m} \mathrm{s}^{-1}\right)$, (c) eastern EIO thermocline depth $(\mathrm{m})$ and $(\mathrm{d})$ eastern EIO precipitation (mm mon ${ }^{-1}$ ) between 1950-2000 and 2045-2095. The red dot and error denote the ensemble mean and standard deviation of differences among the models, respectively. The gray dot, a major outlier, is excluded for ensemble mean. From Zheng et al. (2013). 


\section{Pacific Mode-Water Ventilation Experiment (P-MoVE)}

Mode waters are an important conduit connecting the Kuroshio Extension to the subtropical countercurrent, an eastward current in the southwestern subtropical gyre against the Sverdrup flow and northeast trade winds (Kobashi and Kubokawa, 2012). The Ocean Warming project plans a field campaign targeted at studying the ventilation and dissipation of the subtropical mode water over the Northwest Pacific. Formed in the winter deep mixed layer south of the Kuroshio Extension, the North Pacific subtropical mode water appears as a thick layer of water of relatively uniform properties. Its core density and temperature are $25.4 \sigma_{\theta}$ and $18^{\circ} \mathrm{C}$ (Oka and Qiu, 2012), respectively.

In climate models, mode waters are a dynamical agent important for decadal climate variability and the response of the central subtropical gyre to global warming over the North Pacific (Xie et al., 2010). Current climate models, however, suffer large biases in representing mode waters (Xu et al., 2012). Specifically the isopycnal PV minimum is too strong in magnitude and too narrow in width compared to observations (Fig.3). The model low-PV water forms in too narrow a region at the cross-point between the outcrop line and winter mixed layer depth front. Its PV dissipates too slowly along the streamline. In observations, the low PV core dissipates rapidly along the mean streamline on the 25.4 isopycnal soon after being subducted into the thermocline. This illustrates that the PV conservation, a key assumption of the ventilated thermocline theory, is not satisfied. What causes the rapid dissipation of the mode water is unclear except that ocean eddies are likely important.

Forming the core of the P-MoVE experiment is an eddy-resolving array of Argo profiling floats in the modewater dissipation region (Fig.5). The Argo floats will be deployed in late March through mid-April 2014 to capture the arrival and evolution of the mode water freshly formed during the winter. During the Argo deployment, concurrent CTD castings and atmospheric GPS soundings will be obtained on R/V DongFangHong. Oxygen sensors will be attached to some floats to identify the freshly formed water masses. To minimize the dispersion, iridium floats will be used. The sampling interval will be reduced to 3 days, permitting observations for one full year.

In addition to the background Argo program (at coarse sampling intervals of $3^{\circ}$ ), the current observing system of the Kuroshio Extension system consists of three moored buoys: J-KEO at $146.5^{\circ} \mathrm{E}, 38^{\circ} \mathrm{N}$ (PI: Toshimi Kawai, www. jamstec.go.jp/iorgc/ocorp/ktsfg/data/jkeo/); KEO at $144.5^{\circ} \mathrm{E}, 32.4^{\circ} \mathrm{N}$ (PI: Meghan Cronin, www.pmel.noaa. gov/keo/); and $\mathrm{S} 1$ at $145^{\circ} \mathrm{E}, 30^{\circ} \mathrm{N}$ (PI: Makio Honda, www.jamstec.go.jp/rigc/e/ebcrp/mbcrt/). Together with PMoVE, they forms an enhanced observing system for the subtropical mode water: KEO and S1 buoys are in the formation and subduction regions, respectively, while the P-MoVE Argo array observes the dissipation. Contacts have been established with KEO and S1 groups to realize the potential of this unprecedented infrastructure.

Other collaborators include the ongoing HotSpot project in Japan, which focuses on the Kuroshio Extension and its interaction with the atmosphere (PI: Hisashi Nakamura, www.atmos.rcast.u-tokyo.ac.jp/hotspot/index_eng. html). Additional resources include the recently completed Kuroshio Extension System Study (KESS; http:// uskess.org/).

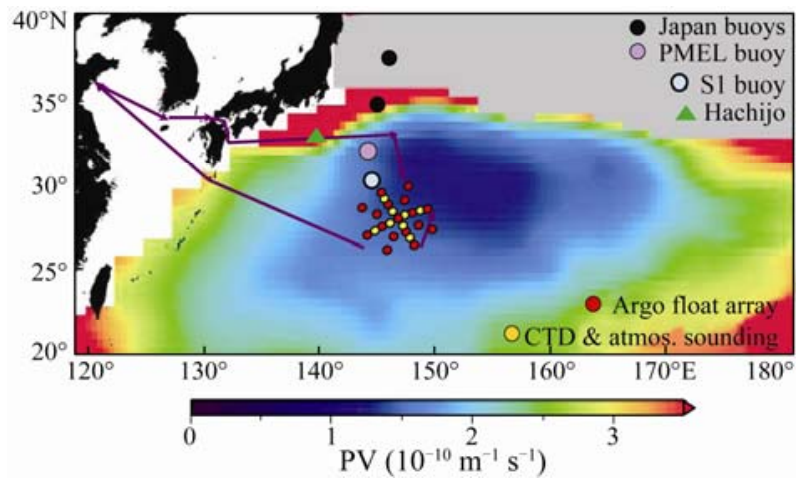

Fig.5 Enhanced Argo array and cruise track of the PMove field experiment to probe the rapid dissipation of low-PV mode water. On the background are the current observing system, and PV on the $25.4 \sigma_{\theta}$ isopycnal.

\section{This Special Issue}

The special issue presents some initial results from the first year of the Ocean Warming project, organized into four sections that roughly follow the project's themes.

Tropical ocean response to global warming Qian and Chen (2013) devised a method to classify observed precipitation changes into-distinct regions by the spatiotemporal characteristies; Yang et al. (2013) evaluated the CMIP5 simulation of precipitation change over the North Indian Ocean in relation to SST change; Zhou et al. (2013) constructed a six-member ensemble of a coupled model simulation and showed intensified (weakened) oceanic (atmospheric) feedback of the IOD mode in response to global warming.

Northwest Pacific The observational study of Liu and $\mathrm{Li}$ (2013) revealed that the subtropical mode water is significantly thicker in anticyclonic eddies than that in cyclonic eddies, suggestive of eddy effects in ventilating the mode water; Xu et al. (2013) showed that the deep winter mixed layer in the Kuroshio Extension region first shoals in response to global warming and then surprisingly deepens gradually as GHG levels off, corresponding to the fast and slow adjustments of the ocean; Wang et al. (2013b) looked into GHG and aerosol effects on the Northwest Pacific mode water formation in an attempt to explain why no major change has been reported about this phenomenon.

Climate variability Xie et al. (2013) investigated ocean-atmospheric processes by which climate anomalies over the North Pacific trigger the development of central Pacific El Niño; Huang et al. (2013b) reported on a strong 
asymmetry between the response of South China Sea SST to El Niño and La Niña; Guo et al. (2013) examined the formation of a barrier layer in the Southeast Arabian Sea during the evolution of a positive IOD event; Liu et al. (2013b) evaluated the CMIP5 simulation of climate modes in the tropical Indo-Pacific Oceans; Liu et al. (2013a) examined the biological response to IOD variability and showed that CMIP5 earth system models succeed in simulating the attendant chlorophyll signals, albeit too strong compared to observations. Yan et al. (2013) examined SST variability in the Southern Hemisphere; Xing and Huang (2013) studied factors influencing tropical cyclogenesis over the Bay of Bengal in May and October.

East Asian climate Liu and Zhang (2013) compared two SST datasets in representing rapid warming of China Seas for the 20th century; Li and Zhang (2013) studied a Yellow-East China sea fog event in terms of SST and atmospheric circulation effects; Wang et al. (2013a) investigated winter-spring atmospheric teleconnections between East Asia and the tropical western Pacific.

Of the 16 papers, three are notable for their innovativeness. Xu et al. (2013) identified two distinct stages of upper-ocean stratification change in response to global warming; Wang et al. (2013b) documented the different response of the Northwest Pacific Ocean to GHG and aerosol forcing; Liu et al. (2013a) looked into newly built earth system models for biological variability tied to physical modes. These studies are still exploratory but that is the spirit of scientific discovery that this project strives to foster.

This special issue represents only a partial snapshot of the progress the Ocean Warming project has achieved. Published elsewhere, Huang et al. (2013a) presented a synergy between the wet-get-wetter and warmer-get-wetter views for rainfall response to global warming. While the warmer-get-wetter pattern dominates annual mean precipitation change, the wet-get-wetter effect is important for the seasonal mean change. In zonal mean, the band of rainfall increase marches back and forth across the equator following the climatological rain band, thus a wet-get-wetter effect (Fig.6). The anomalous rain band is displaced equatorward of the climatological one, an effect of anomalous ascending motions anchored by the equatorial peak in SST warming.

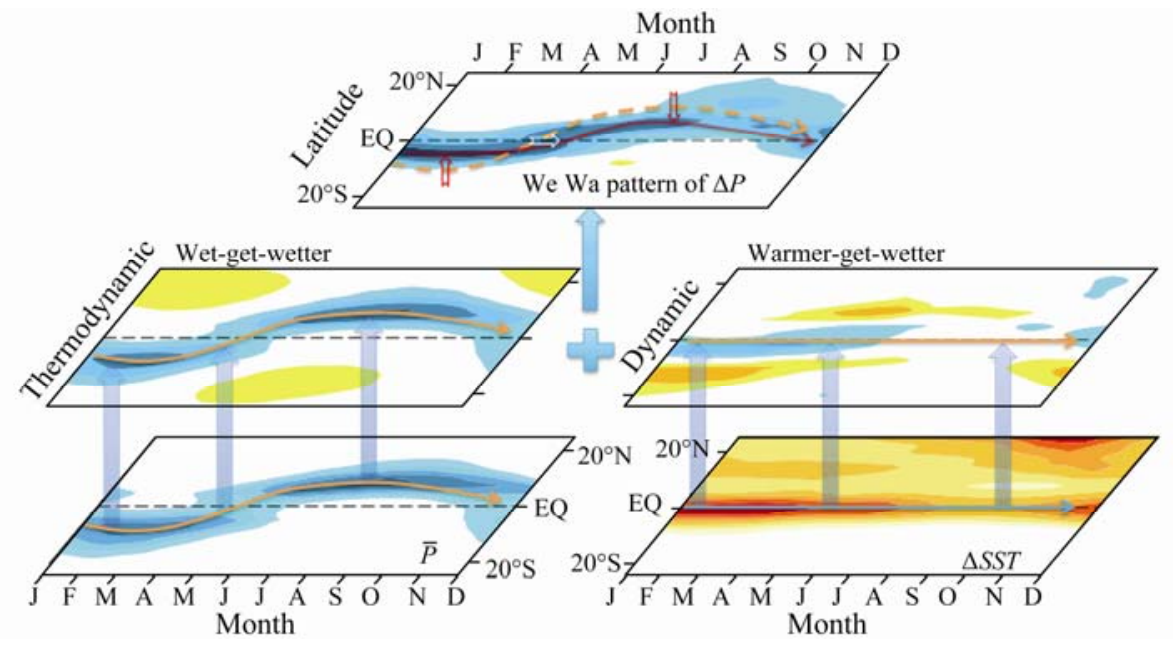

Fig.6 Time-latitude sections: (top panel) rainfall response to global warming in coupled models, (left middle) its thermodynamic and (right middle) dynamic components. (Right bottom) Rainfall climatology, and (right bottom) SST change. See Huang et al. (2013a) for detail.

\section{Acknowledgement}

I wish to thank Qinyu Liu and many other project team members for constructive discussions; Xiaotong Zheng for making Fig.1, Lixiao Xu for Fig.3, Peiliang Li and Fumiaki Kobashi for Fig.5, Ping Huang for Fig.6; Yuan Peng of the Project Office for coordinating manuscript submission, and reviewers for maintaining a high standard. This work is supported by the National Basic Research Program of China (2012CB955600). Visit http:// globalwarming973.ouc.edu.cn/ for more information on the Ocean Warming project.

\section{References}

Aldy, J. E., and Stavins, R. N., 2012. Climate negotiators create an opportunity for scholars. Science, 337: 1043-1044.

Allen, M. R., Frame, D. J., and Mason, C. F., 2009. The case for mandatory sequestration. Nature Geoscience, 2: 813-814.

Cai, M., 2005. Dynamical amplification of polar warming. Geophysical Research Letters, 32, L22710, DOI: 10.1029/ 2005GL024481.

Cai, W., Lengaigne, M., Borlace, S., Collins, M., Cowan, T., McPhaden, M. J., Timmermann, A., Power, S., Brown, J., Menkes, C., Ngari, A., Vincent, E. M., and Widlansky, M. J., 2012. More extreme swings of the South Pacific convergence zone due to greenhouse warming. Nature, 488: 365-369.

Cane M. A., Clement, A. C., Kaplan, A., Kushnir, Y., Pozdnyakov, D., Seag $\equiv$, Zebiak, S. E., and Murtugudde, R., 1997. Twentieth-cenzary sea surface temperature trends. Science, 275: 957-960, DOI: 10.1126/science.275.5302.957

Chadwick, R., Boutle, I., and Martin, G., 2013. Spatial patterns of precipitation change in CMIP5: Why the rich don't get richer in the tropics. Journal of Climate, DOI: 10.1175/JCLI- 
D-1112-00543.00541, In press.

Chang, P., Yamagata, T., Schopf, P., Behera, S. K., Carton, J. A., Kessler, W. S., Meyers, G., Qu, T., Schott, F. A., Shetye, S., and Xie, S.-P., 2006. Climate fluctuations of tropical coupled system: The role of ocean dynamics. Journal of Climate, 19: 5122-5174.

Collins, M., An, S.-I., Cai, W., Ganachaud, A., Guilyardi, E., Jin, F.-F., Jochum, M., Lengaigne, M., Power, S., Timmermann, A., Vecchi, G., and Wittenberg, A., 2010. The impact of global warming on the tropical Pacific Ocean and El Niño. Nature Geoscience, 3: 391-397.

Deser, C., Knutti, R., Solomon, S., and Phillips, A. S., 2012. Communication of the role of natural variability in future North American climate. Nature Climate Change, 2: 775-779, DOI: $10.1038 /$ nclimate1562.

Deser, C., Phillips, A. S. and Alexander, M. A., 2010. Twentieth century tropical sea surface temperature trends revisited. Geophysical Research Letters, 37, L10701, DOI: 10.1029/ 2010GL043321

Domingues, C. M., Church, J. A., White, N. J., Gleckler, P. J., Wijffels, S. E., Barker, P. M., and Dunn, J. R., 2008. Improved estimates of upper-ocean warming and multi-decadal sea-level rise. Nature, 453: 1090-1094.

Du, Y., Yang, L., and Xie, S.-P., 2011. Tropical Indian Ocean influence on Northwest Pacific tropical cyclones in summer following strong El Niño. Journal of Climate, 24: 315-322.

Durack, P. J., Wijffels, S. E., and Matear, R. J., 2012. Ocean salinities reveal strong global water cycle intensification during 1950-2000. Science, 336: 455-458.

Guo F. Y., Liu, Q. Y., Zheng, X. T., and Sun, S., 2013. The role of barrier layer in the Southeastern Arabian Sea during the development of positive Indian Ocean Dipole events. Journal of Ocean University of China, 12 (2), DOI: 10.1007/s11802013-2170-4.

Han, W. Meehl, G. A., Rajagopalan, B., Fasullo, J. T., Hu, A., Lin, J., Large, W. G., Wang, J.-W., Quan, X.-W., Trenary, L. L., Wallcraft, A., Shinoda, T., and Yeager, S., 2010. Patterns of Indian Ocean sea-level change in a warming climate. Nature Geoscience, 3: 509-584.

Held, I. M., and Soden, B. J., 2006. Robust responses of the hydrological cycle to global warming. Journal of Climate, 19: 5686-5699.

Held, I. M., Winton, M. Takahashi, K., Delworth, T., Zeng, F., and Vallis, G. K., $20 \equiv$ robing the fast and slow components of global warming by returning abruptly to preindustrial forcing. Journal of Climate, 23: 2418-2427.

Huang, P., Xie, S.-P., Hu, K., Huang, G., and Huang, R., 2013a. Patterns of the seasonal response of tropical rainfall to global warming. Nature Geoscience, in press.

Huang, Z., Du, Y., Wu, Y. L., and Xu, H. M., 2013b. Asymmetric response of the South China Sea SST to El Niño and La Niña. Journal of Ocean University of China, 12 (2), DOI: 10.1007/s11802-013-2169-x.

Hulme, M., O’Neill, S. J., and Dessai, S., 2011. Is weather event attribution necessary for adaptation funding? Science, 334: 764-765.

Johanson, C. M., and Fu, Q., 2009. Hadley cell widening: model simulations versus observations. Journal of Climate, 22: 27132725.

Johnson, N. C., and Xie, S.-P., 2010. Changes in the sea surface temperature threshold for tropical convection. Nature Geoscience, 3: 842-845.

Kerr, R. A., 2011. Humans are driving extreme weather; time to prepare. Science, 334: 1040-1040.
Knutson, T. R., Sirutis, J. J., Garner, S. T., Vecchi, G. A., and Held, I. M., 2008. Simulated reduction in Atlantic hurricane frequency under twenty-first-century warming conditions. Nature Geoscience, 1: 359-364.

Kobashi, F., and Kubokawa, A., 2012. Review on North Pacific subtropical countercurrents and subtropical fronts: role of mode waters in ocean circulation and climate. Journal of Oceanography, 68: 21-43.

Kosaka, Y., Xie, S.-P., Lau, N.-C., and Vecchi, G. A., 2013. Origin of seasonal predictability for summer climate over the Northwestern Pacific. Proceedings of the National Academy of Sciences of the United States of America, to be accepted.

Levitus, S., Antonov, J. I., Boyer, T. P., and Stephens, C., 2000. Warming of the world ocean. Science, 287: 2225-2229.

Li, M., and Zhang, S. P., 2013. Impact of sea surface temperature front on stratus-sea fog over the Yellow and East ChinaA case study with implications for climatology. Journal of Ocean University of China, 12 (2), DOI 10.1007/s11802013-2218-5.

Li, H., Dai, A., Zhou, T., and Lu, J., 2010. Responses of East Asian summer monsoon to historical SST and atmospheric forcing during 1950-2000. Climate Dynamics, 34: 501-514, DOI: $10.1007 / \mathrm{s} 00382-008-0482-7$.

Lin, I.-I., Wu, C.-C., Pam, F., and Ko, D.-S., 2008. Upper ocean thermal structure and the western North Pacific category-5 typhoons. Part I: Ocean features and category-5 typhoon's intensification. Monthly Weather Review, 136: 3288-3306.

Liu, C., and Li, P. L., 2013. The impact of meso-scale eddies on the subtropical mode water in the western North Pacific. Journal of Ocean University of China, 12 (2), DOI: 10.1007/ s11802-013-2223-8.

Liu, L., Feng, L., Yu, W. D., Wang, H. W., Liu, Y. L., and Sun, S W., 2013a. The distribution and variability of simulated chlorophyll concentration over the tropical Indian Ocean from Five CMIP5 models. Journal of Ocean University of China, 12 (2), DOI: 10.1007/s11802-013-2168-y.

Liu, Q. Y., and Zhang, Q., 2013. Analysis on Long-term change of sea surface temperature in the China Seas. Journal of Ocean University of China, 12 (2), DOI: 10.1007/s11802-0132172-2.

Liu, Q. Y., Guo, F. Y., and Zheng, X. T., 2013b. Relationships of interannual variability between the equatorial Pacific and tropical Indian Ocean in 17 CMIP5 models. Journal of Ocean University of China, 12 (2), DOI: 10.1007/s11802-013-2195-8.

Liu, Z., Vavrus, S., He, F., Wen, N., and Zhong, Y., 2005. Rethinking tropical ocean response to global warming: The enhanced equatorial warming. Journal of Climate, 18: 46844700.

Lu, J., and Zhao, B., 2012. The oceanic feedback in the climate response to doubling $\mathrm{CO}_{2}$. Journal of Climate, 25: 7544-7563, DOI: 10.1175/JCLI-D-11-00712.1.

Lu, J., Vecchi, G. A., and Reichler, T., 2007. Expansion of the Hadley cell under global warming. Geophysical Research Letters, 34, L06805, DOI: 10.1029/2006GL028443.

Luo, Y., Liu, Q., and Rothstein, L. M., 2009. Simulated response of North Pacific mode waters to global warming. Geophysical Research Letters, 36, L23609, DOI: 10.1029/2009GL040906.

Lyman, J. M., Good, S. A., Gouretski, V. V., Ishii, M., Johnson, G. C., Palmer, M. D., Smith, D. A., and Willis, J. K., 2010. Robust warming of the global upper ocean. Nature, 465: 334337.

Ma, J., and Xie, S.-P., 2013. Regional patterns of sea surface temperature change: A source of uncertainty in future projections of precipitation and atmospheric circulation. Journal of 
Climate, DOI: 10.1175/JCLI-D-12-00283.1, in press.

Manabe, S., and Stouffer, R. J., 2007. Role of ocean in global warming. Journal of the Meteorological Society of Japan, 85B: $385-403$

Merrifield, M. A., 2011. A shift in western tropical Pacific sea level trends during the 1990s. Journal of Climate, 24: 41264138.

Min, S.-K., Zhang, X., and Zwiers, F. W., 2008. Human induced Arctic moistening. Science, 320: 518-520, DOI: 10.1126/science. 1153468

Oka, E., and Qiu, B., 2012. Progress of North Pacific mode water research in the past decade. Journal of Oceanography, 68: 5-20.

Qian, C. C., and Chen, G., 2013. Warmer-get-wetter or Wet-getwetter? A criterion to partition ocean $\equiv$ cipitation. Journal of Ocean University of China. In press.

Shin, S.-I., and Sardeshmukh, P. D., 2011. Critical influence of the pattern of tropical ocean warming on remote climate trends. Climate Dynamics, 36: 1577-1591, DOI: 10.1007/s00382009-0732-3.

Stevenson, S. L., 2012. Significant changes to ENSO strength and impacts in the twenty-first century: Results from CMIP5, Geophysical Research Letters, 39, L17703, DOI: 10.1029/ 2012GL052759.

Timmermann, A., McGregor, S., and Jin, F.-F., 2010. Wind effects on past and future regional sea level trends in the southern Indo-Pacific. Journal of Climate, 23: 4429-4437.

Tokinaga, H. et al., 2012a. Regional patterns of tropical Indo-Pacific climate change: Evidence of the Walker Circulation weakening. Journal of Climate, 25: 1689-1710.

Tokinaga, H., and Xie, S.-P., 2011: Weakening of the equatorial Atlantic cold tongue over the past six decades. Nature Geoscience, 4: 222-226.

Tokinaga, H., Xie, S.-P., Deser, C., Kosaka, Y., and Okumura, Y. M., 2012b. Slowdown of the Walker circulation driven by tropical Indo-Pacific warming. Nature, 491: 439-443, DOI: 10.1038/nature11576.

Vecchi, G. A., and Soden, B. J., 2007a. Global warming and the weakening of the tropical circulation. Journal of Climate, 20: 4316-4340.

Vecchi, G. A., Soden, B. J., Wittenberg, A. T., Held, I. M., Leetmaa, A., and Harrison, M. J., 2006. Weakening of tropical Pacific atmospheric circulation due to anthropogenic forcing. Nature, 441, DOI: 10.1038/nature04744.

Vecchi, G. A., and Soden, B. J., 2007b. Effect of remote sea surface temperature change on tropical cyclone potential intensity. Nature, 450: 1066-1070.

Wang H., Liu, Q. Y., and Zheng, J., 2013a. Formation mechanism for the anticyclonic circulation anomaly over northeast Asia and the Japan Sea in boreal winter 1997/98 and spring 1998. Journal of Ocean University of China, 12 (2), DOI: 10.1007/s11802-013-2233-6.

Wang L. Y., Liu, Q. Y., Xu, L. X., and Xie, S.-P., 2013b. Response of mode water and subtropical countercurrent to greenhouse gas and aerosol forcing in the North Pacific.
Journal of Ocean University of China, 12 (2), DOI: 10.1007/ s11802-013-2193-x.

Wang, B., Lee, J., Kang, I., Shukla, J., Park, C., Kumar, A., Schemm, J., Cocke, S., Kug, J., Luo, J., Zhou, T., Wang, B., Fu, X., Yun, W., Alves, O., Jin, E., Kinter, J., Kirtman, B., Krishnamurti, T., Lau, N., Lau, W., Liu, P., Pegion, P., Rosati, T., Schubert, S., Stern, W., Suarez, M., and Yamagata, T., 2009. Advance and prospectus of seasonal prediction: assessment of the APCC/CliPAS 14-model ensemble retrospective seasonal prediction (1980-2004). Climate Dynamics, 33: 93-117.

Woollings, T., Gregory, J. M., Pinto, J. G., Reyers, M. and Brayshaw, D. J., 2012. Response of the North Atlantic storm track to climate change shaped by ocean-atmosphere coupling. Nature Geoscience, 5: 313-317.

Xie R. H., Huang, F. and Ren, H. L., 2013. Subtropical air-sea interaction and development of Central Pacific El Niño. Journal of Ocean University of China, 12 (2), DOI: 10.1007/ s11802-013-2143-7.

Xie, S.-P., Hu, K., Hafner, J., Tokinaga, H., Du, Y., Huang, G., and Sampe, T., 2009. Indian Ocean capacitor effect on Indo-western Pacific climate during the summer following El Niño. Journal of Climate, 22: 730-747.

Xing, W., and Huang, F., 2013. Influence of summer monsoon on asymmetric bimodal pattern of tropical cyclogenesis frequency over the Bay of Bengal. Journal of Ocean University of China, 12 (2), DOI: 10.1007/s11802-013-2219-4.

Xu, L. X., Xie, S.-P., and Liu, Q. Y., 2013. Fast and slow responses of the North Pacific mode water and subtropical countercurrent to global warming. Journal of Ocean University of China, 12 (2), DOI: 10.1007/s11802-013-2189-6.

Xu, L.X., Xie, S.-P., and Liu, Q., 2012. Mode water ventilation and subtropical countercurrent over the North Pacific in CMIP5 simulations and future projections. Journal of Geophysical Research-Oceans, 117, C12009, DOI: 10.1029/2012 JC008377.

Yan, L., Du, Y., and Zhang, L., 2013. Southern Ocean SST variability and its relationship with ENSO on Inter-Decadal time scales. Journal of Ocean University of China, 12 (2), DOI: 10 1007/s11802-013-2262-1.

Yang Y. L., Du, Y., Zhang, Y. H., and Cheng, X. H., 2013. Recent changes of northern Indian Ocean summer rainfall based on CMIP5 multi-model. Journal of Ocean University of China, 12 (2), DOI: 10.1007/s11802-013-2269-7.

Zheng, X. T., Xie, S.-P., Vecchi, G. A., Liu, Q., and Hafner, J., 2010. Indian Ocean dipole response to global warming: Analysis of ocean-atmospheric feedbacks in a coupled model. Journal of Climate, 23: 1240-1253.

Zheng, X.-T., Xie, S.-P., Du, Y., Liu, L., Huang, G., and Liu, Q., 2013. Indian Ocean Dipole response to global warmir $\Longrightarrow$ the

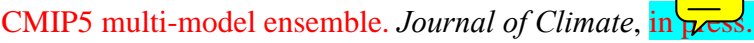

Zhou Z.-Q., Xie, S.-P., Zheng, X.-T., and Liu, Q. Y., 2013. Indian Ocean dipole response to global warming: A multimember study with CCSM4. Journal of Ocean University of China, 12 (2), DOI: 10.1007/s11802-013-2200-2.

(Edited by Xie Jun) 